\title{
25
}

\section{A Method to Assess the Impacts of Climate Change on the Reliability of Stormwater Infrastructure Components}

\author{
Darryl W. Dormuth
}

In recent years, there has been a growing interest to understand how climate change will affect the management of urban drainage systems. The performance assessment of urban stormwater infrastructure requires precipitation data on a spatial scale of tens of square kilometres and on a range of time scales from $15 \mathrm{~min}$ to $24 \mathrm{~h}$. However, the spatial and temporal averaging methods that are used by global climate models (GCMs) to predict precipitation are typically of the order of a few hundred square kilometers, and of months or seasons respectively. This mismatch of spatial and temporal scales has prompted research to bridge the gap and produce rainfall intensity-duration-frequency (IDF) relationships that can be used to assess the impacts of climate change on stormwater infrastructure.

In this chapter, a method is presented that takes a different approach to address this gap. Instead of looking at the effects of climate change on the return period (frequency) of different intensity-duration rainfall events, the effects of climate change on component reliability are examined. This is accomplished by relating component reliability to intensity-duration values using the hydraulic risk function, the extreme value (type I) distribution (EVD-I), and historical rainfall data. To examine the effects of climate change on component reliability, historical rainfall data are used to ascertain the mean and standard deviation of the EVD-I for hourly rainfall extremes and then a correction factor, based on physical constraint governed by the Clausius-Clapeyron relation, is applied to

Dormuth, D. 2010. "A Method to Assess the Impacts of Climate Change on the Reliability of Stormwater Infrastructure Components." Journal of Water Management Modeling R236-25. doi: 10.14796/JWMM.R236-25.

(C) CHI 2010 www.chijournal.org ISSN: 2292-6062 (Formerly in Dynamic Modeling of Urban Water Systems. ISBN: 978-0-9808853-3-0) 
these distributions to determine the change in component reliability. With these correlations and the intensity-duration-reliability functions, one can examine how changes in climate parameters, which are provided by GCMs, influence changes in component reliability. This is demonstrated using hourly rainfall data from five cities on the Canadian prairies.

\subsection{Climate Change and Urban Drainage}

In the Fourth Assessment Report (AR4) of the Intergovernmental Panel on Climate Change (IPCC), changes in the hydrological cycle are discussed in relation to changes in radiative forcing caused by anthropogenic greenhouse gases in the earth's atmosphere (Trenberth et al., 2007). Increased radiative forcing increases surface temperature, which affects evaporation, and it increases air temperature, which increases the capacity of air to hold moisture. Together these affect the characteristics of precipitation, namely type, amount, frequency, intensity, and duration of events and it is the latter three characteristics that will likely be most affected by climate change (Trenberth et al., 2003; Allen and Ingram, 2002).

The extent to which climate change will alter hydrological cycles for different regions of the planet is an area of active research. Ideally, forecasts of climate variables (e.g. temperature and precipitation) should be constrained by solid physical principles, accurate climate observations, and possibly (although not necessarily) by computer simulations (Allen and Ingram, 2002). However, simulations alone from existing atmosphere-ocean general circulation models (AOGCMs) are not enough to predict the range of climate variable responses because they were not designed to do so; they provide best-estimate predictions based on a limited set of observations and not a probabilistic range of predictions $(\mathrm{ibid})$. As a consequence, the forecasts of global-mean temperatures are likely to be better constrained than for any other climate variable, including precipitation, because of the physical constraint of global energy conservation and because the global historical temperature record is more accurate than for any other climate variable (ibid).

Allen and Ingram (2002) provide a thorough discussion on the constraints of hydrological indicators. Observations of relative humidity indicate that at the higher latitudes it remains quite constant through large temperature changes that occur during the seasonal cycles and that at lower latitudes it seems to change little under modeled global warming scenarios. A constraint of constant relative humidity implies that specific humidity (which dictates the moisture available to precipitate) increases exponentially with temperature, as the Clau- 
sius-Clapeyron relation implies. This relation shows that there would be a $6.5 \%$ increase in the global-mean precipitation per Kelvin increase in global-mean temperature in response to the doubling of $\mathrm{CO}_{2}$ in the earth's atmosphere. However, the AOGCM ensemble results show a smaller increase of $3.4 \%$ in global-mean precipitation per $\mathrm{K}$. This is because the overall intensity of the hydrologic cycle is controlled by available energy (Boer 1993), specifically the ability of the troposphere to radiate away the latent heat generated by condensation, rather than by available moisture.

Due to the fact that the intensity of the hydrologic cycle is governed by available energy and not by available moisture means that, although the influence of external forcing on global-mean land precipitation has been detected, $\mathrm{CO}_{2}$ is less effective in driving changes in precipitation than changes in globalmean temperature. This is because an increase in $\mathrm{CO}_{2}$ decreases the net outgoing radiation through the top of the troposphere (tropopause) but increases the downward infrared flux to the earth's surface. As a consequence of these competing effects, $\mathrm{CO}_{2}$ is less effective than other short-wave forcing in driving precipitation changes, which to date have be dominated by natural forcing (solar and volcanic) that vary on shorter time scales. Allen and Ingram (2002) suggest that because global-mean land precipitation is constrained by available energy and because the $\mathrm{CO}_{2}$ forcing on precipitation is weak the observations of recent changes in global-mean temperature and ocean heat capacity should be used to constrain predictions of future changes in global-mean land precipitation and not observations in recent precipitation changes.

While the global-mean precipitation is constrained by available energy, the heaviest rainfalls are expected to occur when nearly all the moisture in a column of air is precipitated out (Trenberth 1999; Allen and Ingram 2002), which means that extreme rainfall events will likely be constrained by available moisture. With this constraint, changes in the upper regions of the precipitation distribution with respect to changes in temperature will be closer to that stated by the Clausius-Clapeyron relation, which is about twice the change for the global-mean precipitation (as discussed above). Trenberth et al. (2003) report a similar value of $7 \%$ increase in heavy rainfall per Kelvin increase in globalmean temperature, with the Clausius-Clapeyron relation, and they postulate that the value could be even higher if the latent heat that is released during condensation feeds back into the storm, further enhancing the convergence of moisture, however, no quantitative estimate of this effect was provided by the authors.

An increase in the ratio of heavy to mean precipitation implies a decrease in light and moderate precipitation or a decrease in the frequency of precipitation events, or both. This, in turn, suggests a future of fewer but more intense pre- 
cipitation events as the global-mean temperature rises. However, it must be recognized that these projected increases in precipitation assume that with the expanding capacity of the air to hold moisture that there is moisture available to occupy the expansion and this is highly dependent on regional effects (see Trenberth et al., 2003, for a thorough discussion of these effects).

So how do these findings translate to the analysis of climate change impacts on urban drainage? Probably the most important implication is that while there has been detection of anthropogenic $\mathrm{CO}_{2}$ forcing on global precipitation over the last century, the influence has been weak (in comparison to natural forcing). However, the balance between these climate drivers is expected to be very different heading into the next century (Hulme et al., 1998) and the influence of anthropogenic $\mathrm{CO}_{2}$ on precipitation changes is projected to be more pronounced. This means that care must be taken in using historical rainfall data to predict changes in future rainfall patterns. This is of particular importance for IDF curves, which are built using historical rainfall data.

Due to the complex physical phenomena that govern precipitation, there are currently no deterministic methods that adequately predict rainfall patterns. Instead rainfall is treated as a stochastic process and the statistical parameters that define this process are derived from historical rainfall records. An example of one such statistic is the exceedance probability, which is the probability that a rainfall event of a specified depth and duration is equalled or exceeded in any year. The inverse of the exceedance probability is the expected return period (or frequency) of the event and it is the depth, duration, and return period, along with frequency analysis methods, that are used to create IDF curves.

As exceedance probabilities (and return periods) are derived from historical rainfall records, the applicability of these values to future events rests on the premise that past rainfall patterns are representative of future ones. As previously discussed, the projected increased forcing of anthropogenic $\mathrm{CO}_{2}$ on precipitation over the next century challenges this premise and, consequently, calls into question the use of current IDF curves to support future risk assessments of urban drainage systems. In Canada efforts are underway in many jurisdictions to update IDF curves (Watt et al., 2003). However, this approach suffers from the same limitation as using contemporary IDF curves: given the transient nature in the changing balance between climate drivers that influence precipitation, the historical rainfall pattern up to any point in time that is chosen to update an IDF curve may not reflect the rainfall pattern from that point forward.

Another issue with regards to IDF curves and climate change is the meaning of frequency in a system that is undergoing a transition from one quasi steady state to (potentially) another. Currently, IDF curves are used to design stormwa- 
ter drainage infrastructure to handle return periods of 1 in $100 \mathrm{y}$ or even longer. However, as mentioned above, in a system that is undergoing a transition the values for these frequencies will depend on the date chosen as the upper bound of the historical record. At this point in time, it seems more appropriate to assign a correction factor to existing IDF curves that is based on the observations reported in (Trenberth at al. 2003; Allen and Ingram) than to update the IDF curves themselves. This is the approach taken in this chapter: a correction factor of a $7 \%$ increase in maximum hourly rainfall per increase in mean annual temperature $(\mathrm{K})$, based on the Clausius-Clapeyron relation, will be applied to hourly-depth versus reliability curves (see next section for more details) for five cities on the Canadian prairies using climate change data from Sauchyn and Kulshreshtha (2007).

\subsection{Methodology}

In this section, a methodology will be described that can be used to assess the potential impact on the hydrologic risk of a stormwater system component due to climate change. The methodology is intended to be straightforward and repeatable and, thus, easy to audit. The methodology requires an existing historical record of rainfall, a function that relates a specified depth and duration to hydraulic risk, using data from the historical record, and a function that relates the change in depth-duration to a climate change parameter.

For the case study in the next section, the EVD-I, also known as the Gumbel distribution, is used. This distribution is employed by Environment Canada (Meteorological Services Canada) (Hogg and Carr, 1985) and most other national meteorological services to describe the frequency of extreme rainfall events. This distribution also has the advantageous feature that it is easy to replace the return frequency parameter with the hydraulic risk parameter (as will be shown). Other distributions exist for the frequency of extreme events and it is believed that they can be used as well; that is, the choice of the EVD-I does not limit the application of this methodology. However, this remains to be proven and will be investigated as part of future research work.

The EVD-I distribution can be expressed as:

$$
X=\mu+K\left(T_{r}\right) \sigma
$$

where

$$
\begin{aligned}
X & =\text { exceedance value } \\
\mu & =\text { population mean, } \\
\sigma & =\text { population standard deviation, }
\end{aligned}
$$


$T=$ return period, and $K\left(T_{r}\right)=$ frequency factor that is defined to be

$$
K\left(T_{r}\right)=\frac{-\sqrt{6}}{\pi}\left(0.5772+\ln \ln \left(\frac{T_{r}}{T_{r}-1}\right)\right)
$$

The mean and standard deviation of the maximum depths, for a specified duration, each year in the historical record are used as unbiased estimators for the population mean, $\mu$, and standard deviation, $\sigma$, in Equation (25.1), respectively:

$$
\begin{aligned}
& \bar{X}_{d}=\left(\sum_{i=1}^{N} X_{d, i}\right) / N \\
& s=\sqrt{\left(\sum_{i=1}^{N}\left(\bar{X}_{d}-X_{d, i}\right)^{2}\right) /(N-1)}
\end{aligned}
$$

where

$$
\begin{aligned}
\bar{X}_{d} & =\text { average maximum rainfall depth for duration } d, \\
X_{d, I} & =\text { maximum rainfall depth for duration } d \text { in year } i, \\
N & =\text { number of years sampled, and } \\
S & =\text { standard deviation of sample. }
\end{aligned}
$$

The series of yearly maximum depths is referred to as the annual series, which is the most commonly used series in extreme value analysis because of data availability and the theoretical basis for extrapolating the series beyond the historical record (Akan and Houghtalen, 2003).

As mentioned in the previous section, climate change predictions indicate that the earth's climate is in the midst of transition from one quasi steady state to (potentially) another. Values of predicted climate variables in the AR4 (Trenberth et al., 2007) are given for different decades (e.g., 2020, 2050) as the earth's climate goes through this transition. In this situation, rather than dealing with the notion of frequency (and thus return period), which is difficult to define for a system in transition, it seems more appropriate to specify a finite time horizon, $M$, and use appropriate values of predicted climate variables and the probability of a rainfall event exceeding a given depth-duration, $J$, for this time horizon. This means that the frequency factor, $K\left(T_{r}\right)$, in Equation 25.2 needs to 
be redefined as a function of $J$ and $M$ instead of the return period $T_{r}$. To do this we make use of the hydraulic risk function (Akan and Houghtalen, 2003):

$$
J=1-\left(1-\frac{1}{T_{r}}\right)^{M}
$$

where

$$
\begin{aligned}
J= & \text { probability of at least one exceedance during the time } \\
& \text { horizon } M \\
T_{r}= & \text { return period, and } \\
M= & \text { specified time horizon. }
\end{aligned}
$$

Equation 25.5 is then rearranged so that $T_{r}$ becomes a function of $J$ and $M$ :

$$
T_{r}=\frac{1}{1-(1-J)^{1 / M}}
$$

Equation 25.6 can then be substituted into the frequency factor, $K\left(T_{r}\right)$, in Equation 25.2 so that the frequency factor becomes a function of $J$ and $M$ :

$$
K(J, M)=\frac{-\sqrt{6}}{\pi}\left(0.5772+\ln \left(-\frac{1}{M} \ln (1-J)\right)\right)
$$

Substituting Equations 25.3 and 25.4 for the population mean and standard deviation and Equation 25.7 for the frequency factor into Equation 25.1, the exceedance value for a given risk factor and specified time horizon can be expressed as:

$$
X=\bar{X}_{d}+K(J, M) s
$$

In Figure 25.1, hourly data from the Regina airport (1960-1994) are used to obtain the mean and standard deviation for Equation 25.8 and three values of $M$ corresponding to $10 \mathrm{y}, 25 \mathrm{y}$ and $50 \mathrm{y}$ are plotted. To read this plot, determine the maximum hourly rainfall capacity that a component can handle (ordinate axis) and the abscissa value that intersects the $J$-Curve (for the desired time horizon $M$ ) is the probability of at least one failure in that time period. For example, a component that can handle a maximum of $40 \mathrm{~mm}$ rainfall in $1 \mathrm{~h}$ has a probability of 0.23 of at least one failure in $10 \mathrm{y}, 0.48$ in $25 \mathrm{y}$ and 0.73 in $50 \mathrm{y}$. 
Regina Airport J-Curves for One-Hour Rainfall

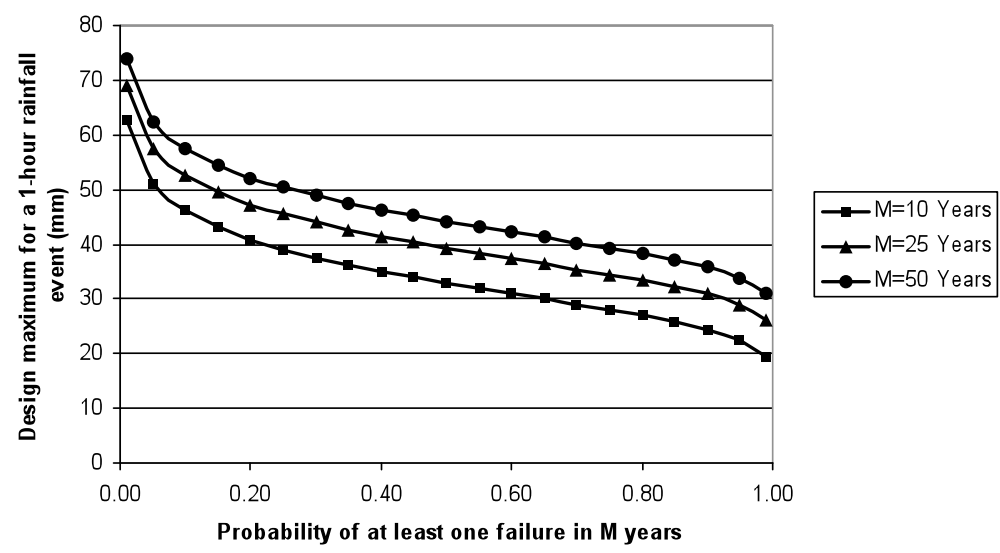

Figure 25.1 Plots of risk of at least one failure versus maximum hourly capacity of a component for 10,25 and 50 years.

The last component of the methodology is to assess the sensitivity of Equation 25.8 to the effects of climate change. This is done in a straightforward manner by including the relation from Trenberth et al. (2003) of a 7\% per Kelvin increase in precipitation into the statistics of Equations 25.3 and 25.4. Let $\Delta T$ be the specified increase in mean annual temperature (from a given reference point) then the statistics in Equations 25.3 and 25.4 can be expressed as follows to include the effects of climate change:

$$
\begin{aligned}
\bar{X}_{d}^{*} & =\left(\sum_{i=1}^{N} X_{d, i}(1+0.07 \Delta T)\right) / N \\
& =(1+0.07 \Delta T)\left(\sum_{i=1}^{N} X_{d, i}\right) / N \\
& =(1+0.07 \Delta T) X_{d}
\end{aligned}
$$

and

$$
s^{*}=\sqrt{\left(\sum_{i=1}^{N}\left(\bar{X}_{d}{ }^{*}-X_{d, i}(1+0.07 \Delta T)\right)^{2}\right) /(N-1)}
$$




$$
\begin{aligned}
& =\sqrt{\left(\sum_{i=1}^{N}(1+0.07 \Delta T)^{2}\left(\bar{X}_{d}-X_{d, i}\right)^{2}\right) / N-1} \\
& =(1+0.07 \Delta T) s
\end{aligned}
$$

By substituting Equations 25.9 and 25.10 into Equation 25.8, it is easily seen that the effect on the exceedance value, $X$, due to an increase in mean annual temperature is simply the multiplication of $X$ by the factor $(1+0.07 \Delta T)$. Therefore, to maintain the same reliability for a stormwater component over a specified time horizon, the capacity of that component must be increased by a factor of $0.07 \Delta T$, where $\Delta T$ is the projected increase in temperature over the time horizon. Evaluation of the change in reliability for a given capacity is not quite as elegant. Given the statistics in Equations 25.3 and 25.4, which are derived from a historical record, the probability of at least one failure during the time span, $M$, for a specified component capacity is $J$. The effect of an increase in $\Delta T$ on the reliability of that component, given that it maintains the same capacity, can be expressed as $J^{*}$ :

$$
J^{*}=1-e^{-M B}
$$

where:

$$
B=e^{c}(-1 / M \ln (1-J))^{(1+0.07 \Delta T)^{-1}}
$$

and

$$
C=\left((1+0.07 \Delta T)^{-1}-1\right)\left(\frac{-\Pi}{\sqrt{6}} \frac{\bar{X}_{d}}{s}+0.5772\right)
$$

As will be shown in the next section, the relationship among the four parameters $J, M, \Delta T$, and $\bar{X}_{d} / s$ that is established in Equations 25.11, 25.12 and 25.13 provides an efficient means of evaluating changes in the reliability of stormwater components due to increases in mean annual temperature.

\subsection{Case Study for Canadian Prairie Cities}

The methodology that was described in the previous section will be used to examine the potential impacts of climate change on component reliability for a one-hour rainfall event for five cities on the Canadian prairies. Hourly rainfall 
data were obtained for Edmonton, Calgary, Saskatoon, Regina and Winnipeg from Environment Canada (see Table 25.1) (Petrou, 2007). From this data, the sample mean and standard deviations were computed for the annual series of the maximum one-hour rainfall depths, for each of the cities. These statistics were used to obtain the baseline EVD-I of one-hour rainfall for each city.

Table 25.1 Statistics derived from historical hourly rainfall record.

\begin{tabular}{lccccc}
\hline \multicolumn{1}{c}{ City } & Station ID & $X_{d}(\mathrm{~mm})$ & $S(\mathrm{~mm})$ & $X_{d} / s$ & Years of Record \\
\hline Edmonton & 3012205 & 13.69 & 5.92 & 2.31 & $1961-1998$ \\
Calgary & 3031093 & 14.04 & 5.94 & 2.36 & $1960-1998$ \\
Saskatoon & 4057120 & 15.66 & 12.92 & 1.21 & $1961-1992$ \\
Regina & 4016560 & 18.95 & 8.96 & 2.11 & $1960-1994$ \\
Winnipeg & 5023222 & 24.61 & 10.91 & 2.26 & $1960-1995$ \\
\hline
\end{tabular}

The latest climate change information for the Canadian prairies is reported in Sauchyn and Kulshreshtha (2007). In this report, scatter plots were produced for the grassland and forest regions of the prairies. As the five major cities are in the grassland region, the projected temperature increase for this region was used. Most of the hourly rainfall data for these cities ends around 1995 so a 25 y time horizon 1995-2020 was chosen for this study. The projected temperature increase by the ensemble of AOGCM models for time period centred around 2020 (which represents the years 2010-2039) is in the range of $1^{\circ} \mathrm{C}$ to $3^{\circ} \mathrm{C}$ (Sauchyn and Kulshreshtha, 2007). Using this temperature range along with the 7\% per Kelvin increase in precipitation that is reported in Trenberth et al. (2003) produces a range of correction factors for the EVD-I from 1.07 to 1.21

A plot of design capacity versus the probability of at least one failure $(J)$ during the period 1995-2020 is provided in Figures 25.2 for the city of Edmonton. Four curves are shown in this plot: the first curve is based on the statistics in Equations 25.3 and 25.4 that are derived from the historical hourly rainfall record for the weather station located at Edmonton's international airport (see Table 25.1); the three other curves are for increases of $1^{\circ} \mathrm{C}, 2^{\circ} \mathrm{C}$ and $3^{\circ} \mathrm{C}$ in mean annual temperature.

As mentioned in the previous section, to maintain the same reliability of a component under an increase in mean annual temperature $(\Delta T)$ the capacity of that component must be increased by a factor of $(1+0.07 \Delta T)$. For example, to maintain a reliability factor of 0.20 the design maximum for a $1 \mathrm{~h}$ rainfall event would have to increase from $32.8 \mathrm{~mm}$ to $35.1 \mathrm{~mm}$ for a $1{ }^{\circ} \mathrm{C}$ increase in mean 
annual temperature, $37.4 \mathrm{~mm}$ for a $2^{\circ} \mathrm{C}$ increase and $39.7 \mathrm{~mm}$ for a $3^{\circ} \mathrm{C}$ increase (as seen in Figure 25.2).

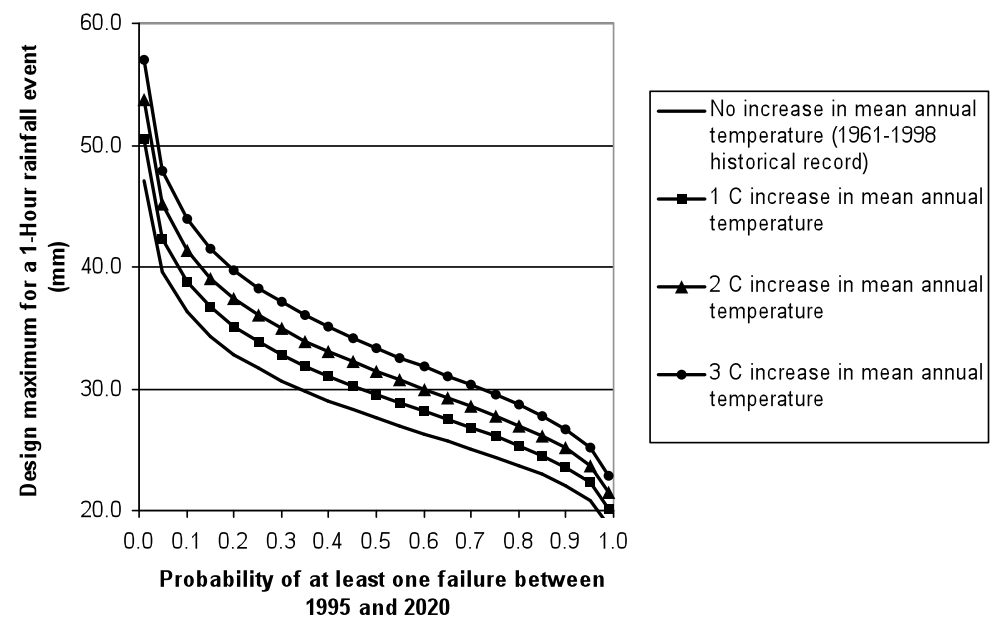

Figure 25.2 The effects of changes in mean annual temperature on component reliability over the period $1995-2020$ for a $1 \mathrm{~h}$ rainfall event at the Edmonton airport.

The curves in Figure 25.2 can also be used to examine the change in reliability for a given design capacity due to an increase in mean annual temperature. As an example, a stormwater component in Edmonton that can handle a maximum capacity of $30 \mathrm{~mm}$ in $1 \mathrm{~h}$ has the probability of at least one failure of 0.33 with no projected increase in mean annual temperature, 0.46 with a $1^{\circ} \mathrm{C}$ increase, 0.60 with a $2^{\circ} \mathrm{C}$ increase and 0.71 with a $3^{\circ} \mathrm{C}$ increase. Although this is shown in Figure 25.2, another way to visualize these changes is to plot the probability of at least one failure over the time period $M$ with no increase in mean annual temperature $(J)$ versus the probability of at least one failure over time period $M$ for increased mean annual temperatures $\left(J^{*}\right)$, as shown in Figure 25.3.

Using the previous example, the probability of at least one failure with no projected increase in mean annual temperature was 0.33 . Using this as the abscissa value and reading upwards on the ordinate axis, the intersections of the curves for increases in the mean annual temperature of $1^{\circ} \mathrm{C}, 2^{\circ} \mathrm{C}$ and $3^{\circ} \mathrm{C}$ correspond to $0.46,0.60$ and 0.71 respectively. Using the curves in Figure 25.3, one can take a design return period $\left(T_{r}\right)$ that is based on historical data, use Equation 
(25.5) to compute its representative $J$-value, and find the changes in component reliability due to increases in the mean annual temperature. For example, if a component is designed for a $20 \mathrm{y}$ return period, this corresponds to a probability of a least one failure in $25 \mathrm{y}$ of 0.72 . Using this as the abscissa value, the probabilities of at least one failure in $25 \mathrm{y}$ due to an increase in mean annual temperature of $1^{\circ} \mathrm{C}, 2^{\circ} \mathrm{C}$ and $3^{\circ} \mathrm{C}$ are $0.83,0.92$ and 0.96 respectively. One could use Equation 25.6 to back out the adjusted return periods, which correspond to about $14 \mathrm{y}, 10 \mathrm{y}$ and $8 \mathrm{y}$ for increases in the mean annual temperature of $1{ }^{\circ} \mathrm{C}, 2^{\circ} \mathrm{C}$ and $3{ }^{\circ} \mathrm{C}$ respectively. However, as discussed in the previous section, the meaning of these return periods needs to be carefully defined as being applicable only to the time span under consideration, which in this case is 1995-2020. It is the author's opinion that the reliability probabilities have a clearer interpretation and should be used instead of return periods.

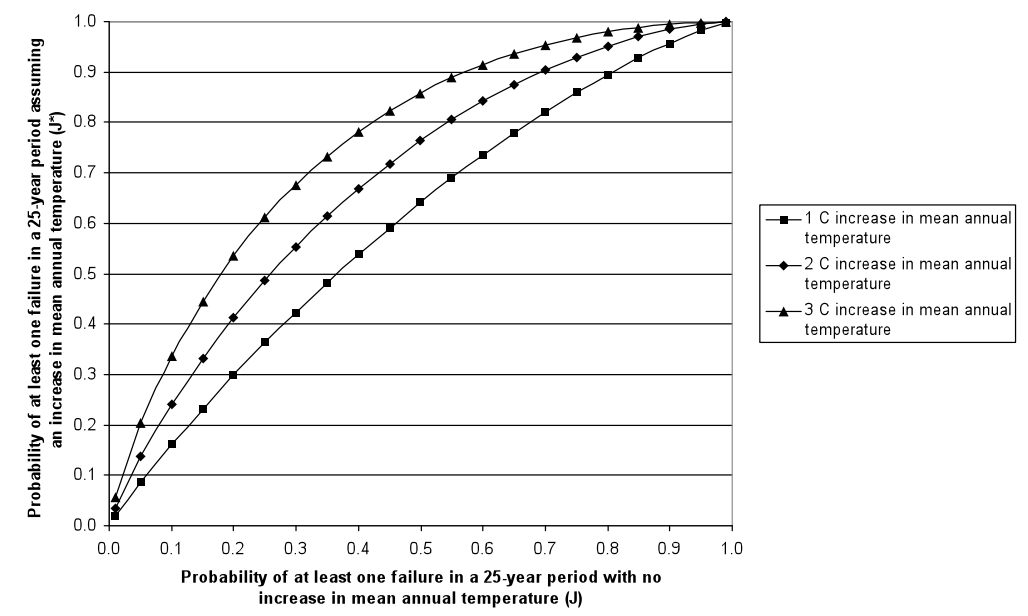

Figure 25.3 Comparison of component reliabilities for changes in mean annual temperature for a $1 \mathrm{~h}$ rainfall event at the Edmonton airport.

One important feature of the relationship among the four parameters $J, M$, $\Delta T$, and $\bar{X}_{d} / s$ that is established in Equations $25.11,25.12$ and 25.13 is that the influence of the historical rainfall record is condensed into a single nondimensional parameter, which is the ratio of the average maximum rainfall depth for duration $d\left(\bar{X}_{d}\right)$ over the standard deviation around this average $(s)$, from the historical record. The larger this ratio is, the greater the change in component reliability. In Table 25.1, these ratios are given for five cities 
on the Canadian prairies and in Figure 25.4 they are used to plot the change in component reliability for a $3^{\circ} \mathrm{C}$ increase in mean annual temperature over a $25 \mathrm{y}$ period for these cities.

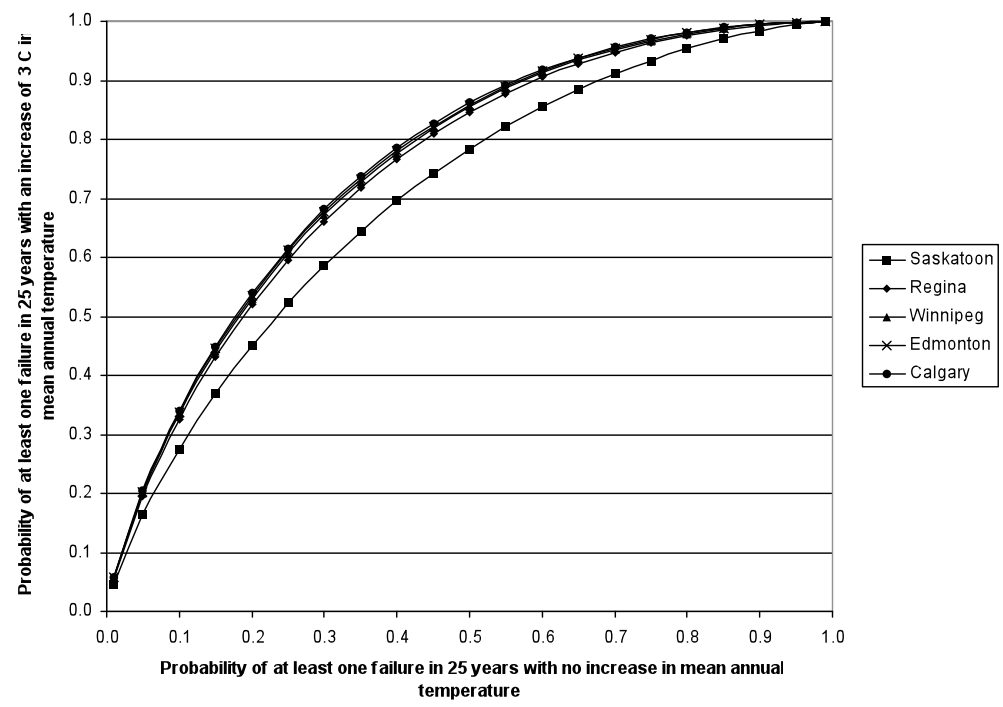

Figure 25.4 Comparison of changes in component reliabilities due to a $3^{\circ} \mathrm{C}$ increase in mean annual temperature for five cities on the Canadian prairies.

The $\bar{X}_{d} / s$ ratios for Edmonton, Calgary, Regina and Winnipeg are very similar and thus produce similar $J^{*}$ curves whereas the ratio for Saskatoon is about half that of the others and there is not as large a change in component reliability as compared to the other cities. The curves in Figure 25.3 would be very similar for Calgary, Regina and Winnipeg. These curves indicate that there will be a significant increase in the failure of stormwater components even for a $1{ }^{\circ} \mathrm{C}$ increase in mean annual temperature. The $J^{*}$ curves for Saskatoon are provided in Figure 25.5 and although the increases in component failure are not as large as those shown in Figure 25.3 they are still significant. Using the same example in reference to Figure 25.3, a component designed for a $20 \mathrm{y}$ return period has a $J$ value of 0.72 and an increase in mean annual temperatures of $1^{\circ} \mathrm{C}, 2^{\circ} \mathrm{C}$ and $3^{\circ} \mathrm{C}$ corresponds to increases in component failure probabilities of $0.81,0.88$ and 0.92 respectively. 


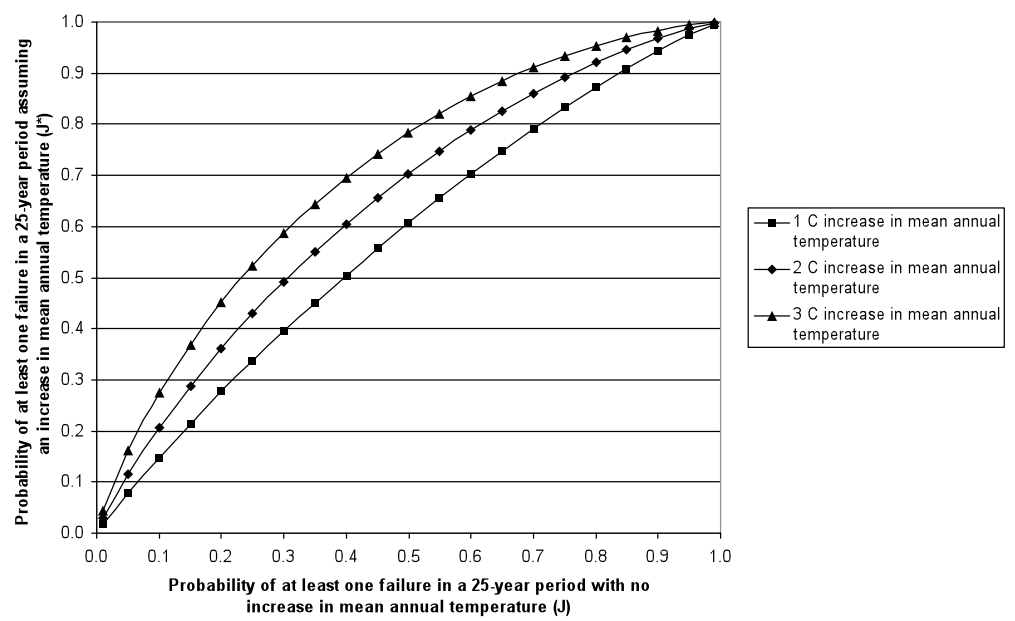

Figure 25.5 Comparison of component reliabilities for changes in mean annual temperature for a $1 \mathrm{~h}$ rainfall event at Saskatoon Airport.

It should also be observed that because the $\bar{X}_{d} / s$ ratio is used in Equations 25.11-25.13 these equations do not depend on the duration $d$; that is, if $\bar{X}_{d 1} / s_{d 1}=\bar{X}_{d 2} / s_{d 2}$ for two different durations $d 1$ and $d 2$ the $J^{*}$ curves will be same for both (provided that $M$ and $\Delta T$ are the same too). Therefore, Equations 25.11-25.13 provide a compact means of analyzing the effects on component reliability because one function applies to any duration of rainfall.

This case study shows that using historical rainfall data, the correction factor that is suggested by Trenberth et al. (2003) to relate the increase in mean annual temperature to an increase in the amount of extreme rainfall, and the EVD-I distribution with a modified frequency factor (Equation 25.7), plots can be easily produced that show the effects of climate change on the reliability of stormwater system components.

\subsection{Summary}

In this chapter, a methodology was presented that relates the potential impact of climate change to the reliability of stormwater system components. This methodology requires an existing historical record of rainfall, a function that relates a specified depth and duration to hydraulic risk (using data from the historical record), and a function that relates the change in depth-duration to a climate 
change parameter. A key objective in the development of this methodology is for it to be straightforward to use and to be repeatable and, thus, easy to audit. This was demonstrated using hourly rainfall data from five cities on the Canadian prairies.

The equations that were derived in Section 25.2 and used in the study in Section 25.3 were based on the assumption that extreme rainfall events can be modeled as a stochastic process based on the EVD-I. The EVD-I was chosen because of its wide use and its mathematical properties that were well suited for the analysis of component failure. There are debates about the applicability of the EVD-I to represent extreme rainfall events and other distributions have been put forward. Future research will look at these distributions to see if relationships among $M, \Delta T$, and the statistics of those distributions can be derived.

Another key assumption that was used in the derivation of the methodology was the relationship between the increase in mean annual temperature and an increase in the percentage of extreme rainfall that was proposed by Trenberth et al. (2003). Although results on climate change impacts were presented in Section 25.3, the main focus of this chapter was on the methodology not on the magnitude of these impacts. A more rigorous analysis needs to be done before any conclusions can be stated about the effect of climate change impacts on stormwater component reliability. This analysis should include a sensitivity study of the parameter relating the increase in mean annual temperature to extreme rainfall and the incorporation of uncertainties of the rainfall measurements, which translate into an uncertainty estimate for the ratio

Future research will also focus on comprehensive risk assessments that use the results from the methodology discussed in this chapter. These risk assessments will examine stormwater systems and use the changes in the probabilities of component failures (Equations $25.11,25.12$ and 25.13) and their associated costs to ascertain the potential economic impact of climate change on these systems.

\section{Acknowledgments}

The National Research Council of Canada (NRC) funded this work through its Centre for Sustainable Infrastructure Research (NRC-CSIR) in Regina, Saskatchewan. The author would like to thank Dr. Yafei Hu and Dr. Imran Syed (NRC-CSIR) for their insightful comments and Ms Maria Petrou at Meteorological Services Canada (Environment Canada) for her help in obtaining the hourly rainfall data that were used. 


\section{References}

Akan, A.O. and Haughtalen, R.J., Urban Hydrology, Hydraulics, and Stormwater Quality: Engineering Applications and Computer Modeling, Wiley.

Allen, M.R. and Ingram, W.J. (2003), Constraints on future changes in climate and the hydrologic cycle, Nature, 419, 224-32.

Boer, G.J. (1993), Climate change and the regulation of the surface moisture and energy budgets, Climate Dynamics, 8, 225-39.

Hogg, W.D. and Carr, D.A. (1985), Rainfall Frequency Atlas of Canada, Atmospheric Environmental Services, Government of Canada.

Hulme, M., Osborn, T.J. and Johns, T.C. (1998), Precipitation sensitivity to global warming: comparison of observations with HADCM2 simulations, Geophysical Research Letters, 25(17), 3379-82.

Petrou, M. (2007), Personal communication, Environment Canada.

Sauchyn, D. and Kulshreshtha, S. (2008), Prairies; in From Impacts to Adaptation: Canada in a Changing Climate 2007, edited by D.S. Lemmen, F.J. Warren, J. Lacroix and E. Bush, Government of Canada, Ottawa, ON, 275-328.

Trenberth, K.E. (1999), Conceptual framework for changes in extremes of the hydrological cycle with climate change, Climatic Change, 42, 327-39.

Trenberth, K.E., Dai, A., Rasmussen, R.M. and Parsons, D.B. (2003), The changing character of precipitation, Bulletin of the American Meteorological Society, 84, $1205-17$.

Trenberth, K.E., P.D. Jones, P. Ambenje, R. Bojariu, D. Easterling, A. Klein Tank, D. Parker, F. Rahimzadeh, J.A. Renwick, M. Rusticucci, B. Soden and P. Zhai,(2007): Observations: Surface and Atmospheric Climate Change. In: Climate Change 2007: The Physical Science Basis. Contribution of Working Group I to the Fourth Assessment Report of the Intergovernmental Panel on Climate Change (Solomon, Qin, Manning, Chen, Marquis, Averyt, Tignor and Miller, Eds.). Cambridge University Press, Cambridge

Watt, W.E., Waters, D., and McLean, R. (2003), Climate change and urban stormwater infrastructure in Canada: context and case studies, Toronto-Niagara Region Study Report and Working Paper Series, Report 2003-1, Meteorological Services of Canada, Waterloo, Ontario. 